\title{
Penentuan Lokasi DG dan Kapasitor Bank dengan Rekonfigurasi Jaringan untuk Memperoleh Rugi Daya Minimal pada Sistem Distribusi Radial Menggunakan Algoritma Genetika
}

\author{
Ridho Fuaddi, Ontoseno Penangsang, Dedet Candra Riawan \\ Jurusan Teknik Elektro, Fakultas Teknologi Industri, Institut Teknologi Sepuluh Nopember (ITS) \\ Jl. Arief Rahman Hakim, Surabaya 60111, Indonesia \\ e-mail:dedet@ee.its.ac.id
}

\begin{abstract}
Abstrak - Jaringan distribusi yang paling umum digunakan ialah sistem dengan bentuk radial. Sistem ini memiliki bentuk yang sederhana serta biaya investasinya yang terbilang murah. Namun, kualitas pelayanan dayanya relatif buruk yang terjadi akibat adanya rugi daya pada saluran yang cukup besar. Hal itu terjadi karena jaringan distribusi yang merupakan ujung dari saluran transmisi memiliki perbandingan rasio $\mathrm{R} / \mathrm{X}$ yang tinggi sehingga mengakibatkan rugi daya yang besar. Terdapat beberapa cara untuk mengurangi rugi daya pada jaringan distribusi yakni dengan menggunakan rekonfigurasi jaringan, pemasangan kapasitor bank dan pemasangan unit distributed generation $(D G)$ pada sistem distribusi. Pada tugas akhir ini, algoritma genetika merupakan metode yang digunakan untuk memecahkan suatu pencarian nilai dalam masalah optimasi penentuan lokasi DG dan kapasitor bank serta rekonfigurasi jaringan yang tepat untuk mendapatkan rugi daya yang paling minimal. Dari hasil pengujian yang telah dilakukan pada penelitian ini, diperoleh perbaikan rugi daya nyata paling optimal sebesar $94,92 \%$ terhadap kondisi awal sistem distribusi radial 33-bus standart IEEE melalui penggabungan pemasangan DG dan kapasitor bank serta rekonfigurasi jaringan.

Kata Kunci : Genetic Algorithm, Distributed Generation, Kapasitor Bank, Rekonfigurasi Jaringan, Sistem Distribusi Radial.
\end{abstract}

\section{PENDAHULUAN}

$\mathbf{J}$ ARINGAN distribusi yang paling umum digunakan ialah sistem dengan bentuk radial. Sistem ini memiliki bentuk yang sederhana serta biaya investasinya yang terbilang murah. Namun, kualitas pelayanan dayanya relatif buruk yang terjadi akibat adanya rugi daya pada saluran yang cukup besar. Hal itu terjadi karena jaringan distribusi yang merupakan ujung dari saluran transmisi memiliki perbandingan rasio $\mathrm{R} / \mathrm{X}$ yang tinggi sehingga mengakibatkan rugi daya yang besar [1]. Terdapat beberapa cara untuk mengurangi rugi daya pada jaringan distribusi yakni dengan menggunakan rekonfigurasi jaringan, pemasangan capacitor bank dan pemasangan unit distributed generation pada sistem distribusi [2]
Rekonfigurasi jaringan merupakan upaya mengubah topologi jaringan dengan cara membuka atau menutup sectionalizing dan tie switch yang terdapat pada saluran. Pada kenyataannya, rekonfigurasi jaringan saja belum mampu mengurangi rugi daya secara signifikan. Sehingga perlu ditambahkan capacitor bank dan distributed generation pada lokasi yang tepat agar diperoleh rugi daya paling minimal [3]. Ketiga cara tersebut diterapkan secara serentak atau simultan pada jaringan distribusi radial. Guna mendapatkan hasil yang optimal, diperlukan suatu metode yang mampu menyelesaikan permasalahan yang bersifat optimasi.

Pada tugas akhir ini, algoritma genetika merupakan metode yang digunakan untuk memecahkan suatu pencarian nilai dalam masalah optimasi penentuan lokasi DG dan kapasitor bank serta rekonfigurasi jaringan yang tepat untuk mendapatkan rugi daya yang paling minimum [4]. Metode ini diterapkan pada jaringan distribusi radial dengan beberapa studi kasus yang berbeda. Dimulai dari penerapan dari masing-masing cara dalam mengurangi rugi daya terhadap sistem yang diujikan hingga penggabungan dari ketiganya yang dilakukan secara serentak. Hasil yang diharapkan nantinya ialah mendapatkan rugi daya terkecil dengan membandingkan setiap studi kasus yang dilakukan.

\section{SISTEM DISTRIBUSI RADIAL, REKONFIGURASI JARINGAN, KAPASITOR BANK DAN DISTRIBUTED GENERATION}

\section{A. Sistem Distribusi Radial}

Sistem distribusi radial merupakan sistem yang paling sering digunakan karena memiliki konfigurasi paling sederhana dan investasi terhadap sistem ini tergolong murah. Sistem tersebut dikatakan radial karena salurannya ditarik secara radial dari suatu titik yang merupakan sumber dari sistem tersebut dan dicabangkan ke titik-titik beban yang dilayaninya.

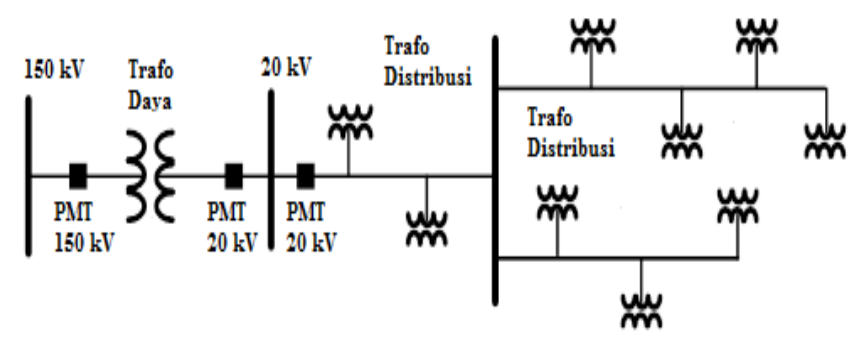

Gambar 1 Sistem Distribusi Radial 150kV/20kV 
Karena hanya ada satu sumber yang menyuplai sistem dan adanya pencabangan ke titik beban yang dilayani, maka arus yang mengalir menuju ke beban disepanjang saluran menjadi tidak sama. Sehingga, luas penampang konduktor pada sistem distribusi radial ini ukurannya tidak sama. Sebab arus yang paling besar ialah yang paling dekat letaknya terhadap gardu induk. Menjadikan saluran yang paling dekat dengan gardu induk memiliki ukuran penampang yang relatif besar dibanding saluran lainnya. Semakin ke ujung maka arus yang menuju ke beban semakin kecil pula. Mengakibatkan luas penampang konduktornya lebih kecil sesuai besar arus yang mengalirinya.

Sistem ini memiliki kekurangan dalam segi kualitas pelayanan daya yang relatif buruk. Hal itu disebabkan oleh rugi daya yang cukup besar, adanya drop tegangan serta besar nilai impedansi pada tiap saluran. Sistem dengan bentuk radial ini memiliki kontinuitas pelayanan daya yang kurang baik. karena hanya memiliki satu alternatif saluran saja. Sehingga ketika terjadi gangguan pada saluran, maka saluran setelahnya akan mengalami pemadaman sampai gangguan dapat diatasi.

\section{B. Rekonfigurasi Jaringan}

Rekonfigurasi jaringan merupakan upaya mengubah topologi jaringan dengan cara membuka atau menutup sectionalizing dan tie switch yang terdapat pada saluran. Cara ini bertujuan untuk mengurangi rugi daya yang ada pada saluran distribusi. Rekonfigurasi atau Konfigurasi ulang jaringan memungkinkan sistem untuk dapat melayani beban yang sama namun dengan rugi daya yang lebih sedikit serta mencegah adanya ketidakseimbangan beban pada sistem distribusi.

Untuk mendapatkan rekonfigurasi jaringan yang paling optimal digunakan konsep branch exchange. Branch exchange merupakan cara yang paling mudah diterapkan pada sistem distribusi radial. Jika salah satu tie switch tertutup, maka akan ada loop yang terbentuk sehingga harus ada saluran dengan sectionalizing switch yang dibuka untuk mengembalikan sistem ke bentuk radial.

\section{Kapasitor Bank}

Kapasitor bank merupakan salah satu komponen yang sering digunakan dalam sistem distribusi listrik. Adapun keuntungan dari penggunaan kapasitor yaitu sebagai berikut:

a. Meningkatkan kemampuan pembangkitan generator.

b. Meningkatkan kemampuan penyaluran daya pada jaringan transmisi.

c. Meningkatkan kemampuan penyaluran daya gardugardu distribusi.

d. Mengurangi rugi-rugi pada sistem distribusi.

e. Menjaga kualitas tegangan pada sistem distribusi.

f. Meningkatkan kemampuan feeder dan peralatan yang ada pada sistem distribusi.

\section{Distributed Generation}

Distributed generation (DG) merupakan pembangkit energi listrik yang berdiri sendiri diluar pembangkit utama pada jaringan. DG terkoneksi dengan sistem distribusi untuk memenuhi kebutuhan konsumen dan memiliki kapasitas pembangkitan lebih kecil dari pada pembangkit energi listrik utama. Pada sistem distribusi, DG umumnya dipasang untuk mengurangi atau menghilangkan rugi daya pada saluran distribusi. Penentuan lokasi, besar kapasitas dan jumlah unit dari DG sangat berperan penting dalam memperoleh rugi daya yang paling minimal pada sistem distribusi.

DG memiliki macam varian kapasitas, mulai dari pembangkitan 1 Watt hingga terbesar yaitu 300MW. Berikut ini merupakan klasifikasi DG berdasarkan kapasitas pembangkitan yang dimilikinya :

Tabel 1 Kategori DG berdasarkan kapasitas

\begin{tabular}{|c|c|}
\hline Jenis DG & Kapasitas Pembangkitan \\
\hline Micro DG & $1 \mathrm{Watt}-5 \mathrm{~kW}$ \\
\hline Small DG & $5 \mathrm{~kW}-5 \mathrm{MW}$ \\
\hline Medium DG & $5 \mathrm{MW}-50 \mathrm{MW}$ \\
\hline Large DG & $50 \mathrm{MW}-300 \mathrm{MW}$ \\
\hline
\end{tabular}

\section{E. Fungsi Objektif}

Pada tugas akhir ini, fungsi objektif yang diinginkan dari penentuan lokasi DG dan kapasitor bank serta rekonfigurasi jaringan ialah total rugi daya nyata yang paling minimal. Upaya yang dilakukan untuk mendapatkan hasil terbaik ditempuh dengan cara memaksimalkan selisih antara rugi daya awal dan rugi daya setelah penempatan DG dan kapasitor bank serta rekonfigurasi terhadap sistem distribusi [5].

Fungsi objektif,

Minimize $P_{T, \text { loss }}=\sum_{k=1}^{n b} \frac{R_{k, k+1}}{\left|V_{k}\right|^{2}}\left(P_{k}^{2}+Q_{k}^{2}\right)$

Dalam upaya untuk memperoleh rugi daya yang paling minimal terdapat batasan atau constraint yang harus dipenuhi, yakni sistem tetap dijaga dalam bentuk radial, batasan daya keluaran DG dan kapasitor serta batasan tegangan yang diizinkan pada tiap bus. Daya keluaran pada DG dan kapasitor bank dibatasai dengan 2 cara :

- Menggunakan rule of thumb [6]

- Menggunakan max demand [7]

Batasan daya keluaran DG dan kapasitor bank menggunakan rule of thumb adalah $2 / 3$ dari total beban daya aktif $(3.715$ MW) dan 2/3 dari total beban daya reaktif (2.3 MVAr) yakni sebesar 2.476 MW dan 1.533 MVAr. Sedangkan, batasan daya keluaran DG dan kapasitor bank menggunakan max demand atau pembebanan maksimum dari sistem sebesar 3.715 MW total beban daya aktif dan 2.3 MVAr total beban daya reaktif.

Batasan tegangan yang diizinkan pada tiap bus dimana selisih antara tegangan tiap bus dengan tegangan sumber yakni 12,66 KV tidak boleh melebihi 5\%. Diharapkan tidak terjadi under voltage ataupun over voltage yaitu tegangan harus berada antara 0.95 p.u dan 1.05 p.u.

$V \min \leq\left|V_{k}\right| \leq V \max$ 
JURNAL TEKNIK ITS Vol. 5, No. 1, (2016) ISSN: 2337-3539 (2301-9271 Print)

\section{PENENTUAN LOKASI DG DAN KAPASITOR BANK SERTA REKONFIGURASI JARINGAN MENGGUNAKAN ALGORITMA GENETIKA}

\section{A. Penerapan Algoritma Genetika(AG)}

Algoritma genetika berdasarkan pada proses genetik yang ada pada makhluk hidup, yakni perkembangan generasi dalam suatu populasi yang alami, secara lambat laun mengikuti prinsip seleksi alam. Dimana hanya individu yang terkuatlah yang mampu bertahan. Algoritma ini bekerja dengan sebuah populasi yang terdiri dari para individu, dimana masing-masing individu merepresentasikan sebuah solusi yang mungkin bagi permasalahan yang ada. Dalam hal ini, individu melambangkan sebuah nilai fitness yang akan digunakan untuk mencari solusi terbaik dari permasalahan.

Berikut ini merupakan gambar diagram alir dari penerapan algoritma genetika dalam menentukan lokasi DG dan kapasitor bank serta konfigurasi jaringan yang tepat untuk memperoleh rugi daya yang paling minimal.

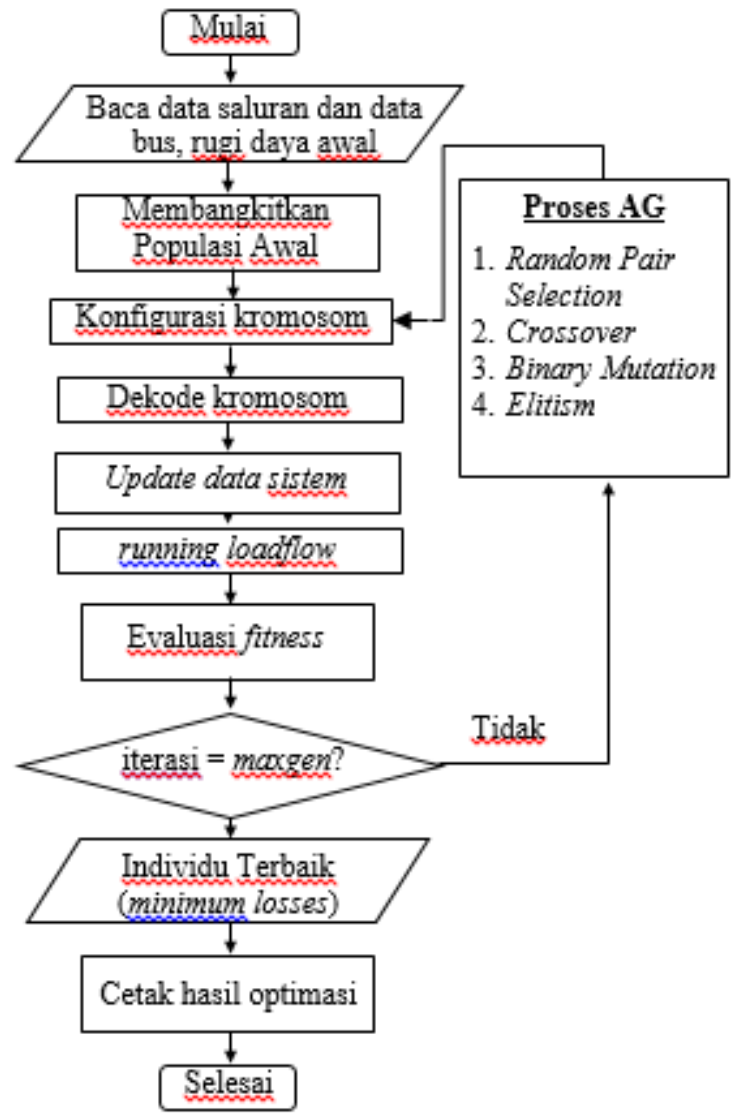

Gambar 2 diagram alir algoritma genetika

Tahapan dari algoritma genetika pada tugas akhir ini :

1. Pembacaan data awal : pembacaan data saluran, data bus dan rugi daya sistem awal.

2. Membangkitkan populasi awal : dalam membangkitkan populasi terdapat variabel yang diperlukan, yakni jumlah DG, jumlah kapasitor, tie switch yang tersedia pada sistem, jumlah individu, generasi maksimal. Individu terdiri kromosom yang dibangkitkan secara acak dan dilakukan konfigurasi kromosom. Kromosom mengangdung informasi lokasi penempatan dan daya keluaran dari DG atau kapasitor bank serta rekonfigurasi jaringan yang di optimalkan.

3. Dekode kromosom : kromosom dalam bentuk biner dterjemahkan ke dalam desimal.

4. Update data sistem : kromosom yang diterjemahkan dimasukkan ke dalam database loadflow

5. Running loadflow : untuk mengetahui rugi daya yang dihasilkan. Loadflow yang digunakan menggunakan metode backward/forward dengan Zbr dan K-matrik

6. Evaluasi fitness : hasil dari running loadflow dievaluasi sesuai constrain yang ditentukan. Jika tidak memenuhi constrain maka tidak akan diambil sebagai solusi

7. Lakukan pengecekkan, apabila belum mencapai iterasi maksimal maka lakukan proses algoritma genetika :

- Seleksi : pemilihan calon orang tua yang akan mengalami proses evolusi dengan metode random selection.

- Cross over : proses cross over/pindah silang yaitu dengan menyilangkan 2 kromosom induk. Proses cross over terjadi berdasarkan nilai probabilitas cross over $(\mathrm{Pc})$ yang telah ditentukan yaitu sebesar 0.95 .

- Mutasi : proses mutasi dalam tugas akhir ini yaitu menggunakan mutasi biner dengan menginvers nilai dari gen yang terpilih dalam kromosom. Proses ini terjadi berdasarkan akan probabilitas mutasi yang ditentukan yaitu sebesar 0.05

- Elitism : merupakan proses untuk mengambil nilai fitness yang paling baik pada tiap generasi untuk dibandingkan dengan nilai fitness terbaik pada generasi selanjutnya. Elitism ini berguna agar individu yang memiliki nilai fitness terbaik tidak berubah saat terjadi proses evolusi pada generasi berikutnya.

Tahap ke-7 terus berlangsung selama generasi belum maksimal dan akan mengulangi dari tahap ke-2 sampai ke-7.

8. Cetak hasil optimasi : hasil berupa lokasi dan daya keluaran DG maupun kapasitor bank serta switch yang akan diputus dan disambungkan.

Algoritma genetika diimplementasikan menggunakan MATLAB version R2010a pada PC ASUS A43S dengan spesifikasi : Processor Core i5 $2.3 \mathrm{Ghz}$, RAM $2 \mathrm{~GB}$.

\section{SIMULASI DAN ANALISIS}

Pada tugas akhir ini, dilakukan simulasi dan analisis terhadap sistem distribusi radial 33-bus standart IEEE dengan 6 kasus yang berbeda, yakni:

- Kasus A : basis sistem (original, tanpa optimasi)

- Kasus B : rekonfigurasi jaringan terhadap basis sistem.

- Kasus C : pemasangan DG terhadap basis sistem.

- Kasus D : pemasangan DG dan rekonfigurasi jaringan terhadap basis sistem.

- Kasus E : pemasangan DG dan kapasitor Bank terhadap basis sistem. 
- Kasus F : pemasangan DG dan kapasitor bank serta rekonfigurasi jaringan terhadap basis sistem.

Hasil yang diperoleh pada tiap kasusnya akan dibandingkan guna mengetahui kasus mana yang memperoleh rugi daya yang paling minimal. Bersamaan dengan itu, akan dibandingkan pula hasil yang diperoleh dari metode yang digunakan dalam menentukan batasan daya keluaran pada DG dan kapasitor bank (kasus C sampai dengan kasus F). Metode yang diterapkan ialah rule of thumb dan max demand. Pada simulasi ini, DG yang digunakan sebanyak 3 unit dan kapasitor bank berjumlah 5 unit. Pada tugas akhir ini DG hanya berfungsi menyuplai daya aktif $(\mathrm{P})$. Sedangkan, kapasitor berfungsi menyuplai daya reaktif (Q).

Pada tugas akhir ini, sistem distribusi radial yang digunakan ialah sistem tes 33-bus standart IEEE. Berikut ini merupakan bentuk topologi sistem beserta data beban dan data saluran yang tersedia yang bersumber dari referensi [1].

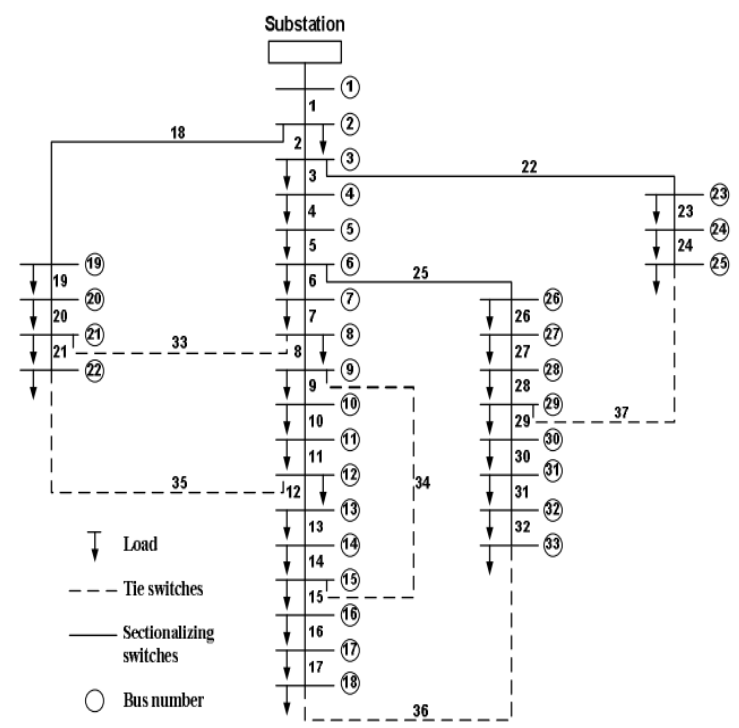

Gambar 3 sistem distribusi radial IEEE 33-bus

Tabel 2 Data beban sistem distribusi 33-bus IEEE [1]

\begin{tabular}{|c|c|c|c|c|c|}
\hline $\begin{array}{c}\text { No. } \\
\text { Bus }\end{array}$ & $\begin{array}{c}\mathrm{P}_{\mathrm{L}} \\
(\mathrm{MW})\end{array}$ & $\begin{array}{c}\mathrm{Q}_{\mathrm{L}} \\
(\mathrm{MVAr})\end{array}$ & $\begin{array}{c}\text { No. } \\
\text { Bus }\end{array}$ & $\begin{array}{c}\mathrm{P}_{\mathrm{L}} \\
(\mathrm{MW})\end{array}$ & $\begin{array}{c}\mathrm{Q}_{\mathrm{L}} \\
(\mathrm{MVAr})\end{array}$ \\
\hline 2 & 0.100 & 0.060 & 18 & 0.090 & 0.040 \\
\hline 3 & 0.090 & 0.040 & 19 & 0.090 & 0.040 \\
\hline 4 & 0.120 & 0.080 & 20 & 0.090 & 0.040 \\
\hline 5 & 0.060 & 0.030 & 21 & 0.090 & 0.040 \\
\hline 6 & 0.060 & 0.020 & 22 & 0.090 & 0.040 \\
\hline 7 & 0.200 & 0.100 & 23 & 0.090 & 0.050 \\
\hline 8 & 0.200 & 0.100 & 24 & 0.420 & 0.200 \\
\hline 9 & 0.060 & 0.020 & 25 & 0.420 & 0.200 \\
\hline 10 & 0.060 & 0.020 & 26 & 0.060 & 0.025 \\
\hline 11 & 0.045 & 0.030 & 27 & 0.060 & 0.025 \\
\hline 12 & 0.060 & 0.035 & 28 & 0.060 & 0.020 \\
\hline 13 & 0.060 & 0.035 & 29 & 0.120 & 0.070 \\
\hline 14 & 0.120 & 0.080 & 30 & 0.200 & 0.600 \\
\hline 15 & 0.060 & 0.010 & 31 & 0.150 & 0.070 \\
\hline
\end{tabular}

\begin{tabular}{|l|l|l|l|l|l|}
16 & 0.060 & 0.020 & 32 & 0.210 & 0.100 \\
\hline 17 & 0.060 & 0.020 & 33 & 0.060 & 0.040 \\
\hline
\end{tabular}

Tabel 3 Data saluran sistem distribusi 33-bus IEEE [1]

\begin{tabular}{|c|c|c|c|c|}
\hline \multicolumn{5}{|c|}{ Sectionalizing Switch } \\
\hline No. Cabang & Bus Kirim & Bus Terima & $\begin{array}{c}\text { Resistansi } \\
\text { R (ohm) }\end{array}$ & $\begin{array}{l}\text { Reaktansi } \\
\text { X (ohm) }\end{array}$ \\
\hline 1 & 1 & 2 & 0.0922 & 0.0470 \\
\hline 2 & 2 & 3 & 0.4930 & 0.2512 \\
\hline 3 & 3 & 4 & 0.3661 & 0.1864 \\
\hline 4 & 4 & 5 & 0.3811 & 0.1941 \\
\hline 5 & 5 & 6 & 0.8190 & 0.7070 \\
\hline 6 & 6 & 7 & 0.1872 & 0.6188 \\
\hline 7 & 7 & 8 & 0.7115 & 0.2351 \\
\hline 8 & 8 & 9 & 1.0299 & 0.7400 \\
\hline 9 & 9 & 10 & 1.0440 & 0.7400 \\
\hline 10 & 10 & 11 & 0.1967 & 0.0651 \\
\hline 11 & 11 & 12 & 0.3744 & 0.1298 \\
\hline 12 & 12 & 13 & 1.4680 & 1.1549 \\
\hline 13 & 13 & 14 & 0.5416 & 0.7129 \\
\hline 14 & 14 & 15 & 0.5909 & 0.5260 \\
\hline 15 & 15 & 16 & 0.7462 & 0.5449 \\
\hline 16 & 16 & 17 & 1.2889 & 1.7210 \\
\hline 17 & 17 & 18 & 0.7320 & 0.5739 \\
\hline 18 & 2 & 19 & 0.1640 & 0.1565 \\
\hline 19 & 19 & 20 & 1.5042 & 1.3555 \\
\hline 20 & 20 & 21 & 0.4095 & 0.4784 \\
\hline 21 & 21 & 22 & 0.7089 & 0.9373 \\
\hline 22 & 3 & 23 & 0.4512 & 0.3084 \\
\hline 23 & 23 & 24 & 0.8980 & 0.7091 \\
\hline 24 & 24 & 25 & 0.8959 & 0.7091 \\
\hline 25 & 6 & 26 & 0.2031 & 0.1034 \\
\hline 26 & 26 & 27 & 0.2842 & 0.1447 \\
\hline 27 & 27 & 28 & 1.0589 & 0.9338 \\
\hline 28 & 28 & 29 & 0.8043 & 0.7006 \\
\hline 29 & 29 & 30 & 0.5074 & 0.2585 \\
\hline 30 & 30 & 31 & 0.9745 & 0.9629 \\
\hline 31 & 31 & 32 & 0.3105 & 0.3619 \\
\hline 32 & 32 & 33 & 0.3411 & 0.5302 \\
\hline \multicolumn{5}{|c|}{ Tie switch } \\
\hline No. Cabang & Bus Kirim & Bus Terima & $\begin{array}{c}\text { Resistansi } \\
\text { R (ohm) }\end{array}$ & $\begin{array}{c}\text { Reaktansi } \\
\text { X (ohm) }\end{array}$ \\
\hline 33 & 8 & 21 & 2.0000 & 2.0000 \\
\hline 34 & 9 & 15 & 2.0000 & 2.0000 \\
\hline 35 & 12 & 22 & 2.0000 & 2.0000 \\
\hline 36 & 18 & 33 & 0.5000 & 0.5000 \\
\hline 37 & 25 & 29 & 0.5000 & 0.5000 \\
\hline
\end{tabular}

\section{Hasil simulasi :}

Pada kasus $\mathrm{A}$ dan $\mathrm{B}$, masing-masing total rugi daya aktifnya adalah sebesar 202,686 KW dan 139,982 KW. Performa dari sistem pada kedua kasus tersebut tak dapat diterima. Karena melanggar batas terendah dari tegangan kerja normal, yakni berada dibawah 0,95. Tegangan yang rendah mengakibatkan lebih banyak arus yang akan diambil dari substation, yang direfleksikan dengan meningkatnya rugi daya. Rekonfigurasi jaringan mampu mereduksi rugi daya aktif sebesar 30,936 \% dari total rugi daya awal sistem, dengan tetap menjaga sistem pada bentuk radialnya. 
Pada kasus C, yakni hanya penempatan DG saja tanpa kapasitor bank dan rekonfigurasi jaringan membantu mereduksi rugi daya aktif sebesar 75,6\% (rule of thumb) dan $72,4 \%$ (max demand) terhadap total rugi daya awal sistem dengan total daya keluaran DG 2,372 MW dan 3,04 MW masing-masingnya. Tegangan pada bus di sistem telah memenuhi constraint, berada pada 0,95-1,05 p.u.

Pada kasus D, rekonfigurasi jaringan dan penempatan DG dilakukan secara simultan. Hasil simulasi memperoleh penurunan rugi daya nyata sebesar 69,646\% (rule of thumb) dan $72,7 \%$ (max demand) terhadap rugi daya awal sistem dengan total daya keluaran DG 2,166 MW dan 2,91 MW masingn-masingnya dengan tetap menjaga bentuk radial dari sistem. Tegangan pada tiap bus di sistem pada kasus ini telah memenuhi batasan yang telah ditetapkan.

Pada kasus E, dimana pemasangan DG dan kapasitor bank secara simultan tanpa rekonfigurasi jaringan mampu memperbaiki rugi daya nyata sebesar $91,81 \%$ (rule of thumb) terhadap rugi daya awal sistem dengan total daya keluaran DG 2,37 MW dan kapasitor bank 1,564 MVAr. Sedangkan, hasil $91,78 \%$ (max demand) diperoleh saat total daya keluaran DG 3,082 MW dan kapasitor bank 2 MVAr. Pada kasus ini, tegangan di tiap bus yang ada sistem berada pada range yang diizinkan.

Pada kasus terakhir, yakni kasus $\mathrm{F}$ saat dilakukan pemasangan DG dan kapasitor bank bersamaan dengan rekonfigurasi jaringan mampu mereduksi rugi daya nyata secara optimal hingga 93,073\% (rule of thumb) dan 94,92\% (max demand) dengan total daya keluaran DG dan kapasitor bank yang diinjeksikan pada masing-masing metode sebesar 2,475 MW dan 1,418 MVAr pada "rule of thumb", sedangkan pada "max demand" sebesar 2,9967 MW dan 1,996 MVAr. Pada kasus ini, rekonfigurasi jaringan dan batasan tegangan pada bus telah memenuhi constraint yang ditetapkan, yakni dengan tetap menjaga sistem distribusi pada pola radialnya dan tegangan pada tiap bus telah berada pada range yang diizinkan.

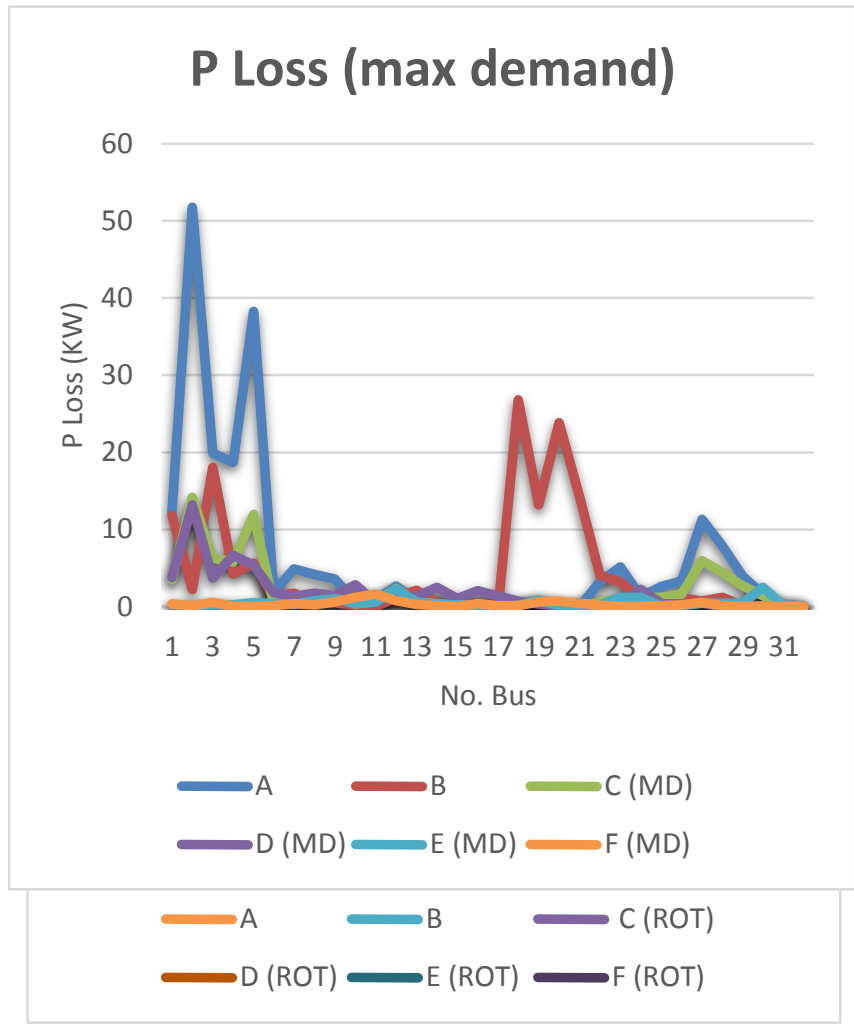

Berikut ini merupakan gambar grafik perbaikan rugi daya dan profil tegangan pada keseluruhan kasus yang telah diujikan.

Gambar 4 rugi daya kasus A-F (rule of thumb) Gambar 5 rugi daya kasus A-F (max demand)

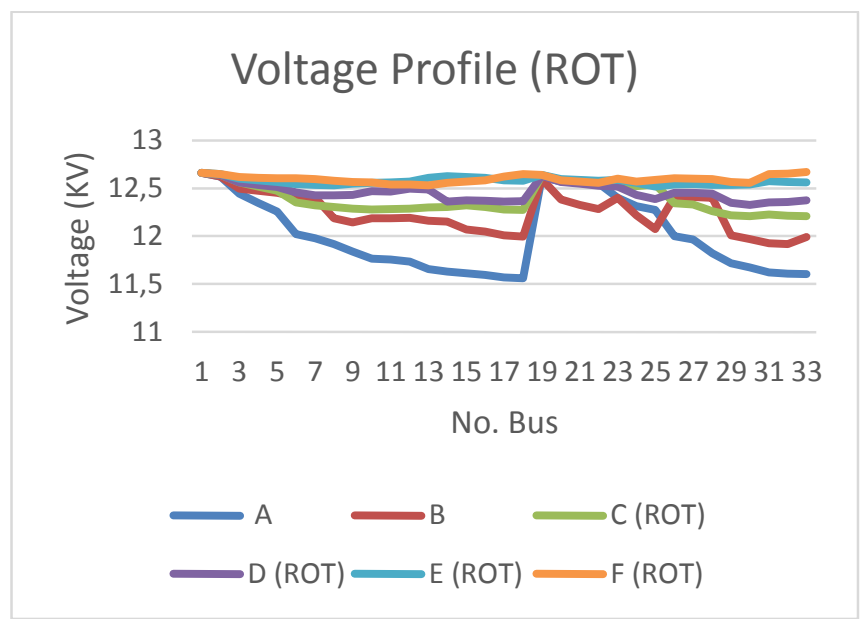

Gambar 6 profil tegangan kasus A-F (rule of thumb) 


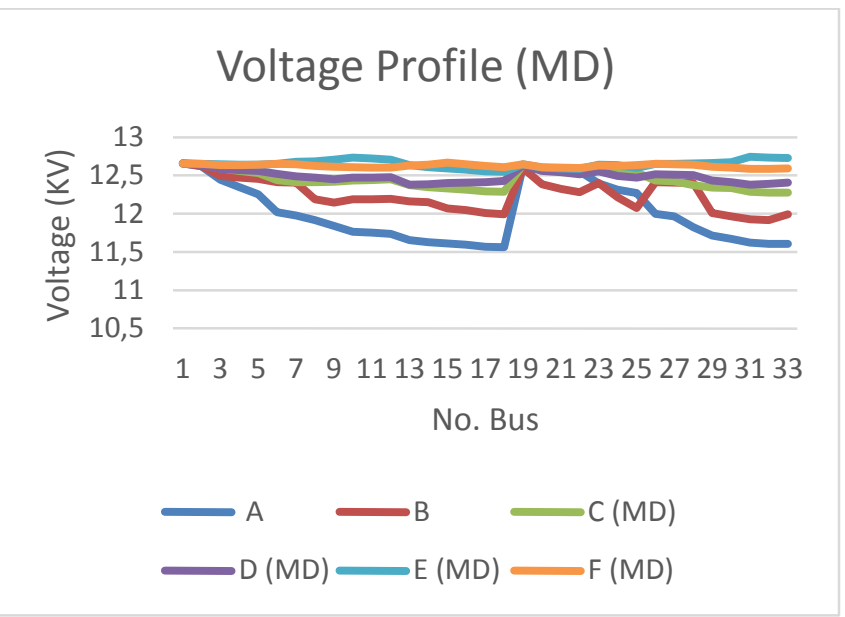

Gambar 7 profil tegangan kasus A-F (max demand) Tabel 4 Hasil optimasi kasus A-F

\begin{tabular}{|c|c|c|c|}
\hline Case & \multicolumn{3}{|c|}{$\begin{array}{c}\text { Comparative Study Of Different Case } \\
\text { Studies }\end{array}$} \\
\hline \multirow{3}{*}{ A } & Methodology & $\begin{array}{c}\text { Max } \\
\text { Demand }\end{array}$ & $\begin{array}{c}\text { Rule of } \\
\text { thumb }\end{array}$ \\
\hline & Switch Opened & $\begin{array}{c}33,34,35 \\
36,37\end{array}$ & $\begin{array}{c}33,34,35 \\
36,37\end{array}$ \\
\hline & $\begin{array}{l}\text { Power Loss } \\
\quad(\mathrm{KW})\end{array}$ & 202.686 & 202.686 \\
\hline \multirow{3}{*}{ B } & Switch Opened & $\begin{array}{c}7,9,14,28, \\
32\end{array}$ & $\begin{array}{c}7,9,14,28, \\
32\end{array}$ \\
\hline & $\begin{array}{l}\text { Power Loss } \\
\quad(\mathrm{KW})\end{array}$ & 139.982 & 139.982 \\
\hline & $\begin{array}{c}\% \text { Loss } \\
\text { Reduction }\end{array}$ & 30,936 & 30,936 \\
\hline \multirow{3}{*}{$\mathrm{C}$} & Switch Opened & $\begin{array}{c}33,34,35 \\
36,37\end{array}$ & $\begin{array}{c}33,34,35 \\
36,37\end{array}$ \\
\hline & $\begin{array}{l}\text { Power Loss } \\
(\mathrm{KW})\end{array}$ & 72.397 & 75.615 \\
\hline & $\begin{array}{c}\% \text { Loss } \\
\text { Reduction }\end{array}$ & 64,28 & 62,69 \\
\hline \multirow{3}{*}{$\mathrm{D}$} & Switch Opened & $\begin{array}{l}9,12,28 \\
30,33\end{array}$ & $\begin{array}{l}11,13,28 \\
30,33\end{array}$ \\
\hline & $\begin{array}{l}\text { Power Loss } \\
(\mathrm{KW})\end{array}$ & 55.3 & 61.523 \\
\hline & $\begin{array}{c}\% \text { Loss } \\
\text { Reduction }\end{array}$ & 72,7 & 69,646 \\
\hline \multirow{3}{*}{$\mathrm{E}$} & Switch Opened & $\begin{array}{c}33,34,35 \\
36,37\end{array}$ & $\begin{array}{c}33,34,35 \\
36,37\end{array}$ \\
\hline & $\begin{array}{l}\text { Power Loss } \\
(\mathrm{KW})\end{array}$ & 16.656 & 16.592 \\
\hline & $\begin{array}{c}\% \text { Loss } \\
\text { Reduction }\end{array}$ & 91,78 & 91,81 \\
\hline \multirow{2}{*}{$\mathrm{F}$} & Switch Opened & $\begin{array}{c}10,28,31, \\
33,34\end{array}$ & $\begin{array}{c}10,13, \\
28,30,33\end{array}$ \\
\hline & $\begin{array}{c}\text { Power Loss } \\
(\mathrm{KW})\end{array}$ & 10,298 & 14.037 \\
\hline
\end{tabular}

\begin{tabular}{|c|c|c|c|}
\hline & $\begin{array}{c}\text { \% Loss } \\
\text { Reduction }\end{array}$ & 94,92 & 93,074 \\
\hline
\end{tabular}

\section{KESIMPULAN}

Berdasarkan hasil simulasi dan analisis yang telah dilakukan, dapat disimpulkan bahwa :

1. Pada basis sistem, terdapat rugi daya aktif sebesar $15,52 \%$ terhadap daya aktif yang disuplai oleh substation (3917,686 watt). Dengan pemasangan DG dan kapasitor bank serta rekonfigurasi jaringan menggunakan metode algoritma genetika diperoleh perbaikan rugi daya aktif yang sangat optimal. Sehingga, rugi daya aktif pada sistem menjadi sangat minimal yakni sebesar $0,79 \%$.

2. Metode yang paling efektif dalam menentukan batas daya keluaran yang dihasilkan DG dan kapasitor untuk memperoleh rugi daya nyata adalah metode rule of thumb. Hal tersebut didasari oleh efisiensi antara rugi daya nyata yang diperoleh terhadap besar total daya keluaran yang dimiliki oleh DG dan kapasitor bank.

3. Penggunaan metode algoritma genetika dapat membantu menyelesaikan permasalahan yang bersifat optimasi, seperti halnya pada tugas ini yang digunakan untuk memperoleh rugi daya nyata yang paling minimal pada sistem distribusi radial yang diujikan.

\section{DAFTAR PUSTAKA}

[1] Saonerkar, A. K. and Bagde, B.Y., "Optimized DG Placement in Radial Distribution System with Reconfiguration and Capacitor Placement Using Genetic Algorithm," in Proc. IEEE Conf. 2014, pp. 1077-1083.

[2] J. Lavaei and S. Low, "Relationship between power loss and network topology in power system," in Proc. IEEE Conf. on Decision and Control, Dec. 15-17, 2010, pp. 4004-4011.

[3] N. Rugthaicharoencheep and W. Wanaratwijit, "Distribution system operation for power loss minimization and improve voltage profile with distributed generation and capacitor placements," in Proc. IEEE Conf. 2011, pp. 1185-1189.

[4] David E. Goldberg, "Genetic Algorithm in Search, Optimization \& Machine Learning," Addison-Wesley, 1989.

[5] Nitin Singh, "Optimal Sizing and Placement of DG in a Radial Distribution Network using Sensitivity based methods", Electrical and Instrumentation Engineering Department Thapar University, Patiala-147004, Punjab, India, July, 2014.

[6] H. L. Willis, "Analytical methods and rules of thumb for modeling DG - distribution interaction," in Proc. IEEE Power Eng. Soc. Summer Meeting, Jul. 2000, pp. 1643-1644.

[7] A. Mohamed Imran, M. Kowsalya, D.P. Kothari, "Optimal Distributed Generation and Capacitor placement in Power Distribution Networks for Power Loss Minimization,” IEEE 2014. 